\title{
PUBLIC-PRIVATE PARTNERSHIPS AND PHYSICAL ACTIVITY: A MATTER OF HEALTH PROMOTION AND CHRONIC DISEASE PREVENTION
}

\section{PARCERIAS PÚBLICO-PRIVADAS E ATIVIDADE FÍSICA: PROMOÇÃO DE SAÚDE E PREVENÇÃO DE DOENÇAS CRÔNICAS}

\author{
Gabriel Natan Pires ${ }^{1,2}$, Diego Roger-Silva ${ }^{3}$
}

\section{ABSTRACT}

Clin Biomed Res. 2021;41(2):170-177

1 Department of Psychobiology, Universidade Federal de São Paulo. São Paulo, SP, Brasil.

2 Department of Physiological Sciences, Santa Casa de São Paulo School of Medical Sciences. São Paulo, SP, Brasil.

3 Department of Rheumatology, Universidade Federal de São Paulo. São Paulo, SP, Brasil.

Corresponding author: Gabriel Natan Pires gnspires@gmail.com Departamento de Psicobiologia, Universidade Federal de São Paulo Rua Napoleão de Barros, 925 04024-002, São Paulo, Brasil.
Public-private partnerships are joint initiatives between the public and private sectors with a specific focus and a defined level of action. Several international reports have shown good results of public-private partnerships using physical activity interventions associated with public health policies and strategies. Among these reports, we highlight those that focus on the prevention of chronic diseases such as cardiovascular disease, diabetes, asthma, and obesity using physical activity as the main tool. This article discusses the conceptual framework behind these partnerships, addressing their possible effectiveness and feasibility. We debate important factors in the success of these partnerships, as well as possible benefits to the public and private entities involved and to the target populations of these interventions.

Keywords: Public-private partnerships; Chronic diseases; Public health; Primary prevention; Physical activity; Exercise

\section{RESUMO}

Parcerias público-privadas são iniciativas organizadas em conjunto por entidades dos setores público e privado, com foco específico e nível de atuação definido. Diversos relatos internacionais demonstram bons resultados das parcerias público-privadas que usam intervenções de atividade física associadas a estratégias ou a políticas de saúde pública. Dentre estas, destacam-se aqueles que focam a prevenção de doenças crônicas, como doenças cardiovasculares, diabetes, asma e obesidade. Este artigo discute os aspectos conceituais que embasam essas parcerias, abordando os fatores que justificam sua eficácia e viabilidade. São debatidos os fatores de sucesso e os possíveis benefícios destas parcerias às entidades envolvidas, sejam elas públicas ou privadas, bem como para a população-alvo destas parcerias.

Palavras-chave: Parceria público-privada; Doenças crônicas; Saúde pública; Prevenção primária; Atividade física; Exercício

\section{INTRODUCTION}

Noncommunicable chronic diseases such as diabetes, asthma, obesity, and cardiovascular disease are related to a great share of overall mortality ${ }^{1}$. These diseases constitute a major public health problem since they are highly prevalent and commonly entail chronic and costly treatments, consequently leading to substantial public expenditure. However, these diseases are highly preventable ${ }^{1-3}$, meaning that it is economically advantageous to invest in public health policies regarding prevention rather than generating costs related to avoidable treatments and secondary health care-related expenses.

Physical activity is widely reported as an efficient method for the prevention of chronic diseases ${ }^{4-6}$. It is estimated to avoid premature mortality in $15 \%$ worldwide ${ }^{7}$. However, the engagement in physical activity by the population is much lower than the recommended levels. Thirty-one percent of the world population is 
estimated to be physically inactive, mainly in the Americas and eastern Mediterranean regions (approximately $43 \%$ ), and this phenomenon is more common among women and in high-income countries ${ }^{8}$. Among the adult population with chronic diseases, the prevalence of physical inactivity is approximately $85 \% 9$. These estimates corroborate the idea of a pandemic of physical inactivity, which accounts for the fourth leading cause of death worldwide ${ }^{10}$.

Increasing physical activity levels in all populations is required to reduce the burden of noncommunicable diseases. The World Health Organization (WHO) Global Action Plan on Physical Activity 2018-2030 established a goal of reducing physical inactivity by $15 \%$ until $2030^{11}$. A comprehensive, integrated, and intersectoral approach is indispensable for achieving this objective, involving individuals and their communities, clinical and health science professionals, and public entities. However, public health policies that employ physical activity for the prevention of chronic noncommunicable diseases seem to be scarce, which could be explained by several factors. Among them, we highlight the need for qualified professionals, specific knowledge on prevention techniques, methodology that suits the social context, and acceptance and compliance by the community ${ }^{2,12}$.

Seeing the main public health policy efforts being directed to treatment instead of prevention, as well as the difficulties in implementing physical activity in public health programs, public-private partnerships (PPPs) may be an interesting alternative. These partnerships are justified when the association of public organizations and private institutions allows both parts to reach goals that would not be viable through uncooperative work ${ }^{13,14}$. According to the Global Plan on Physical Activity ${ }^{11}$, changing the current physical inactivity condition demands partnerships between multiple players from both the public and private sectors, as the aimed goals would hardly be achievable by a single entity. Indeed, there are interesting reports in which these partnerships are related to physical activity ${ }^{15-18}$. This study aims to present the importance of public-private partnerships in health promotion through physical activity. A comprehensive overview of some successful examples of PPPs that promote physical activity interventions has been recently published $^{19}$. Therefore, instead of reviewing cases, we will focus on the conceptual framework behind these PPPs, discussing their main characteristics and the benefits of their implementation to the public and private entities, as well as to the target population.

\section{PUBLIC-PRIVATE PARTNERSHIPS}

The technical definition of a PPP varies broadly among different authors, areas of knowledge, and countries $^{14,19}$. In practical terms, these partnerships are joint initiatives between 2 sectors (public and private), with a specific focus (e.g., health, economics, politics), and in a given level of action (e.g., local, national, global $)^{2}$, being better contextualized as a mutual interest relationship rather than a sponsorship or service-providing contract.

Legal descriptions may apply in some cases, which might lead to slightly different and more restrictive definitions. For example, according to the Brazilian legislation ${ }^{20}$, "the PPP is an administrative concession contract, in sponsored or administrative modalities." In Australia, "a PPP is a service contract between the public and private sectors where the Australian Government pays the private sector to deliver infrastructure and related services over the long term" 21 . In Canada, PPPs are considered "an infrastructure delivery model that integrates the various phases of the asset life cycle into one long-term performance-based agreement," in which "the government can transfer to the private sector many of the risks and responsibilities of the design, construction, financing, operation and maintenance of federal infrastructure ${ }^{22}$. As these legal definitions have limited applicability out of their respective jurisdiction, we will consider the broader and practical definition described in the previous paragraph.

Public health has always been one of the main action focuses of PPPs (along with infrastructure, technology, services, and other fields) ${ }^{23}$. There are several reports on PPPs and public health, encompassing various areas (e.g., oral health ${ }^{24}$ and obesity ${ }^{25}$ ), levels of action (e.g., local ${ }^{15}$, state ${ }^{16}$, and global ${ }^{24}$ ), and in many different places (e.g., the United States ${ }^{16}$, Canada $^{26}$, and Africa ${ }^{27}$ ).

\section{PUBLIC-PRIVATE PARTNERSHIPS AND PHYSICAL ACTIVITY}

Physical activity is one of the possible action points for public health-oriented PPPs. Regarding PPPs specifically related to this subject, there are reports of projects devoted to the prevention of cardiovascular diseases, obesity, diabetes, and other conditions ${ }^{15,17,28}$, as well as of some projects generically devoted to promoting physical activity regardless of a specific diagnosis or clinical condition ${ }^{29-31}$. These reports include partnerships between governments and large international companies ${ }^{18,25}$, as well as small-sized entities with limited local relevance ${ }^{32,33}$.

Despite the increasing importance gained by this issue, the number of reports of PPPs related to public health and physical activity is still modest. Indeed, it seems that this kind of partnership has not yet been converted into a common public health strategy. This can be explained by 2 main hypotheses: (1) these partnerships, under the concept of health promotion, 
do not exist due to the lack of public incentive or private interest; (2) these partnerships do exist, but their methodology and results are not dully reported to the academic-scientific community.

To better analyze the possibilities and suitability of such partnerships, all the involved parties should be understood and contextualized. A general definition of the 3 parties possibly involved in physical exerciserelated PPPs is presented below.

Public entity: The public partner involved in a PPP is usually the government or a governmentrelated institution, on its multiple possible levels (from the local/municipal to the national level). Depending on the legislation, non-legislative entities might also act as public partners in PPPs, including specific services within the government and public schools or universities, as long as they hold formal ties with the government. In nontraditional cases, nongovernmental entities are considered public partners in PPPs if their participation is not profit-oriented and is directed to the good of a given public, community, or population. Some examples include international not-for-profit organizations, philanthropic organizations, universities and academic groups, global physical activity or sport-related institutions, professional associations, and social groups, which might be considered public entities in PPPs when associated with private entities to incentivize specific physical activity practices.

Private entity: The private partner is conditionally a for-profit organization, with no formal ties to the government. In most cases, the main business activity of the private entity is directly related to sports or physical activities. Examples include sports equipment manufacturers, retailers, sport facility operators, health club chains, and professional sport teams. Although less common, the private entity could be not primarily related to physical activity. Examples include media and broadcast companies, which might work to promote health benefits related to regular physical activity.

Public: Every PPP approaching physical activity must have a well-defined target public to whom the initiative and its activities will be directed. This public might vary considerably, depending on the coverage and aims of the PPP. Broader national and international PPPs may have the whole population as their target, whereas local PPPs focus on a specific community. Additionally, this target population may be unspecific (e.g., all individuals who go jogging on a given park) or restricted to a given characteristic (e.g., children in the public education system; older individuals). Finally, despite being uncommon, a PPP might be directed to a specific professional segment instead of the whole population (e.g., physical activity interventions for professional drivers in the public transportation service). In any case, the public should be the final common goal of every physical activity-related PPP.

\section{IMPORTANT CHARACTERISTICS TO THE SUCCESS OF PPPS}

One of the main strengths of PPPs is their ability to reach goals that would hardly be reached without cooperative work ${ }^{13,14}$. This way, considering the main model of PPPs related to health promotion and physical education, benefits for private entities include the access to a wide audience provided by the government, which is a very efficient way to expose and publicize their services and brands. Conversely, the government relies on the experience and skilled labor offered by private entities to provide the public with efficient and accessible services ${ }^{34}$. McKinnon ${ }^{12}$ exemplifies this relationship, stating that public health and the economy are inseparable. According to this author, when considering the increasing importance of chronic disease and its associated expenses to public health, only the alliance between public and private sectors would be able to ensure high-quality health promotion services at low costs.

Although there is evidence on the reliability of physical activity-related PPPs within public health policies, it is understandable that they are not being employed or, at least, having a difficult start ${ }^{35}$. This can be partially explained by the common perception of the public sector regarding private initiatives, classifying them as biased to maximize profits. On the other hand, the private sector regards the rules and laws imposed by the government as bureaucratic obstructions ${ }^{12}$. Despite generalizations, these statements are usually true. Similarly, differences between the public and private sectors concerning operational principles, methods, and goals are generally an obstacle to the establishment of a PPP. While public health services are primarily sustained by long-term projects, with gradual and slow progress, private initiatives usually prefer immediate and short-term results ${ }^{35}$. In summary, the differences between public and private entities span their missions, perspectives, and institutional culture, and the suspicion between the involved parts affects the elaboration and consolidation of PPPs. However, avoiding the establishment of such partnerships and consequently depriving the community of their potential benefits is unacceptable from a public health perspective ${ }^{35}$.

In the face of the presented difficulties, McKinnon ${ }^{12}$ sets 6 basic steps for the success of PPPs, which are briefly presented below:

\section{1. "Doing good" and "making money" are not} mutually exclusive but rather complementary. Despite the apparent conflict between effective work, sought by public policies, and profitable work, pursued by private entities, both can be achieved by means of a PPP. By assigning due value to the work, reasons, and perspectives 
of all parts involved, both sectors can achieve their aims.

2. Leverage differences. By granting value to others' work and understanding it as distinguished, both involved parts might benefit from the partnership. A PPP draws upon differences to reach goals that would not be possible with individual or uncooperative work.

3. Do not let perfectionism hinder progress. When we recognize that the aims of public and private entities may be divergent, both parts should understand the other's interests. This way, they might become concessive and start looking forward to a well-balanced relationship.

4. Design well. Even considering that both the public and private sectors are aware of the benefits of PPPs and understand the importance of mutually valuing the performed work, the success of a PPP will depend on an analysis of the aims and roles of both parts, contextualizing them within the partnership. The partnership should thus be well-designed and structured before the actual work begins. The development phase of a PPP is essentially more important than the actual implementation phase.

5. Manage expectations. In PPPs related to public health and physical activity, success will not depend only on the efforts of the involved parts. Some external factors should be considered, such as the compliance by the community, the assiduity of participants, and other peculiarities of the target population. Considering the example of a PPP intending to prevent childhood obesity through physical activity, its success would depend on the compliance of the kids, the interest of their parents, their eating habits, and even on their anthropometric profile. Taking these variables into account, reaching the initial goals may become more expensive, slower, and harder than previously planned.

6. Share aims. Although both sectors have interests in a PPP, some common goals can be established to make these partnerships more productive. However, common goals that are important to both parts may not be so evident at first. As an example, in the case of a PPP intending to decrease the risk of cardiovascular events by means of guided walks, the decrease in the incidence of these events is a common goal even though the reasons why each part seeks it are different. In this case, the public entity benefits through public health policies, leading to a reduction in expenses with medications and mortality indices. On the other hand, private entities benefit by demonstrating the efficacy of their methods and the quality of their work to the general population.

The aforementioned basic principles are highly important in the creation and success of PPPs. Even so, one must bear in mind that such partnerships involve many other factors. In general, these principles are common to most health-related PPPs. However, each PPP has its own characteristics and peculiarities, depending on the target populations, intended interventions, and expected goals.

\section{BENEFITS TO THE INVOLVED PARTIES}

No partnership is established if the involved parts do not foresee their benefits. In a PPP, the 3 parties involved are entitled to different benefits: some appear in the short term and others become evident only in the long term. A description of the main benefits of PPPs for the 3 involved parties (public entities, private entities, and the population) is disclosed below.

\section{Public entities}

The establishment of PPPs directed towards health promotion through physical activity may represent some risks to the government, as these are nontraditional strategies that are quite different from usual public health policies. However, the perspective of benefits may overcome such potential risks ${ }^{2}$, especially in the long term. Possible benefits are:

Operational Risks: In PPPs, public entities benefit from the expertise and qualification of the private part. Therefore, risk perspectives decrease and most of these risks are transferred to the private entity, mainly concerning the accomplishment of goals, deadlines, and execution ${ }^{26,35}$. This way, by relying on the expertise and background of the private partner (as well as on a recommendable history of successful cases), the operational risks involved in an intervention are substantially reduced. When goals are not reached, both parties may be held responsible, and secondary costs and deficits might be shared.

Costs: According to Silversides ${ }^{26}$, the change from traditional public health policies to PPPs may lead to increased costs, mainly due to the funder and supporter role played by the public domain in most partnerships. This means that hiring or partnering with a private entity to perform a physical activity intervention might be more expensive than performing it directly with public resources and personnel. This statement is rebutted by Majestic ${ }^{36}$, who considers that, in the face of elevated expenses with public health and the overall tendency of decreasing public income, the establishment of PPPs may be a good alternative under a long-term public health perspective. In the specific 
case of physical activity-related PPPs, it seems clear that the reduction in general expenses is natural, as such projects generally employ low costs and easily applicable methodologies. When considering the massive public expenses in the treatment of chronic diseases ${ }^{2}$, such partnerships represent an interesting and economic alternative for the public system ${ }^{36}$.

Public health policies: Although PPPs are not common strategies when compared to traditional public health policies ${ }^{2}$, one should not be considered an alternative to the other, as they are not mutually exclusive. Instead, both should be used cooperatively in a way that PPPs can act as an adjuvant to more traditional strategies. Additionally, such partnerships might lead to long-term public health achievements ${ }^{35}$, such as reductions in health-related costs, the number of occupied hospital beds, and morbidity and mortality related to chronic diseases, especially in cases where the PPP focuses more on prevention than on treatment.

\section{Private entities}

Private entities might have access to different benefits by adhering to the PPP model. Such benefits are briefly discussed below:

Brand exposure: By adhering to a PPP, private entities promote their brand and methodologies to different sectors of the population, especially when working directly with the community and demonstrating the benefits they have to offer. This is an interesting strategy to generate brand awareness, especially for smaller or arriving brands or companies. However, in order for this brand exposure to achieve positive results, the results of the PPP should be satisfactory from the perspective of the customers (ie, the population). In case of failure, noncompliance with previously disclosed aims, or poor execution of the planned activities, the effects of being part of a PPP might be counterproductive due to the risk of associating the brand with negative results ${ }^{26}$.

Brand loyalty: For well-known brands, more than creating brand awareness, it is important to establish itself as a major player among the competitors, reinforcing its prominent position, and thus leading to customer loyalty. As this is more applicable to leading brands, this strategy aims more at keeping customers engaged in their brands than acquiring new ones (despite this being equally possible). As an example, we might mention the cases of international sport equipment manufacturers promoting sport-related activities in public parks or professional sport teams promoting physical activity initiatives and reinforcing their bonds with fans.

Assessing government information: By means of a PPP, the private entity might gain access to government information or at least to valuable data related to the behavior and health status of a specific community. In some cases, access to such information might be defined by contract in a way that the public entity provides data to the private entity, as this might be important in the design and development of the partnership. In these cases, the provided information might include socioeconomic data, encompassing not only those attending the initiative but also a whole community or population. Alternatively, the private entity might have access to the information of only those individuals who attended the partnership, which would result in information about this community's behavior, engagement, and health status. In any case, government or population information is a valuable source of data to be used for strategic planning, aiming at matching a giving service or product to the community's needs and profile. This specific topic is subjected to privacy and data protection legislation, which might vary considerably from one country to another.

Financial and economic factors: Low-sized entities, usually involved in PPPs at local or regional levels, normally have their participation and operational costs fully covered by public entities. In this sense, the PPP might be profitable in the short term due to the limited margin for loss and because many PPPs might establish a profit margin directly from the public entity. In the long term, the PPP might be profitable in the sense that the private entity might use it for branding purposes, promoting its services directly to customers. Therefore, for local or regional PPPs, the profit perspective is positive in both the short and long terms. For larger private entities involved in PPPs from state to international levels, the degree of support by public entities might vary. It is common to have private entities as co-supporters that bear a good amount of operational costs. In this sense, these partnerships might lead to a net deficit in the short term. However, in the long term, the profit margin is substantially larger than in the short term in a way that it is proportional to the reach of the PPP, since it depends on the size of the target population that will have access to it and to whom the private entities will expose their brands and services. Consequently, larger PPPs might not lead to short-term profits, but financial benefits tend to be larger in the long term. In any case, both smaller (local to regional) and larger (state to international) PPPs are associated with good profits for private entities ${ }^{36}$.

Social responsibility: Demonstrating social responsibility is an indirect way to increase the reputation of a company. Customer evaluations tend to be better whenever a company commits with social responsibility goals. Therefore, although PPPs might involve short-term deficits, they might lead to brand awareness and loyalty, thus leading to long-term benefits. They can also be understood as a matter of corporative ethics, which also adds value to a brand. In 
some cases, the partnership can be shaped as a way of extending a brand's main activity to the population (e.g., a running shoes manufacturer promoting guided walks to the population). In others, it may appear as a damage reduction strategy (e.g., a soda brand promoting physical activity interventions to prevent childhood obesity). In any case, demonstrating social responsibility is usually a duty of every large company and is commonly established in their statutes, and engaging in physical activity-related PPPs is an option to put this into practice.

\section{Population}

Benefits to the population are the final goals in these partnerships. For public entities, it is interesting to use PPPs to reduce the incidence, prevalence, and health care costs of chronic diseases. On the other hand, for private entities, interest comes from the understanding that the population is a potential long-term customer. In this sense, although both parts establish a PPP on their own benefit, they perform it aiming at benefits to the population. Some of these benefits are listed below.

Better health-related conditions: This benefit is evident, since it is directly related to the primary goals of a PPP, but depends on the success and efficacy of the partnership. There are multiple reports in which PPPs employing physical activity led to a better health condition of the population by preventing chronic diseases such as obesity, asthma, and cardiovascular disorders ${ }^{25,32}$. Secondary consequences should also be accounted for, including better access to health services and increased quality of life and wellbeing.

Reduced individual health care-related expenses: Regardless of the public health policies of each country, people commonly seek health insurances and private appointments or services. This is amplified in the case of chronic diseases, where appointments and the demand for health services might become systematic. By investing in initiatives that focus on the prevention of these diseases, the demand and need for such services might be reduced, making health care more affordable to the population. Considering the PPPs related to physical activity practices, evidence indicates that they are able to reduce these costs ${ }^{36}$. Concurrently, the simple fact that physical activity would be offered to a share of the population that would not have access to such services by other means is an important benefit on its own.

\section{CHALLENGES TO PHYSICAL ACTIVITY- ORIENTED PPPS}

The literature is rich on examples of positive and successful PPPs related to physical exercise, and very few cases of unsuccessful partnerships have been reported. This is probably a case of publication bias, mainly related to the private sector within the PPPs. The likelihood of reporting the results of a PPP on an academic journal is reasonably higher when positive results have been reached. As these players are not primarily academic institutions, they are not committed to disclosing and reporting the results of a PPP when they are not attractive. An independent evaluation of the results of PPPs (when an analysis of its outcomes is made by a third party other than the public and the private entities involved) is more likely to disclose negative aspects and poor results, and a few cases have already been published ${ }^{37,38}$.

This represents a case of conflict of interests, in which the decision to publish the results of a PPP is only made when they are already known. We are then left with a partial and biased view of the effectiveness of PPPs dealing with physical activity. Consequently, we are not able to evaluate the proportion of success cases among the published PPPs or the reasons for their eventual failure.

In any case, a few general challenges faced by physical activity-oriented PPPs take place mainly during the starting and implementation phases, but can be extended to their whole duration. Joudyian et al..$^{23}$ analyzed 61 PPPs and grouped these challenges into five categories: education/awareness, management, human resources, financial resources, and information and technology systems. While they were thought for overall primary health care PPPs, they can be contextualized to physical activity promotion.

Education/Awareness: Both public and private entities might engage in and become responsible for tasks on which they do not have sufficient knowledge. Additionally, the public might not be educated on or aware of the availability, goals, or benefits of a PPP-related project.

Management: The results of a PPP depend on how it is managed, which might lead to several challenges. Lack of collaboration, commitment, and strategic vision by both partners might hinder the possible success of a PPP. Roles, teams, and expectations should be defined beforehand so that the project can be effectively managed.

Human resources: Lack of proper training and knowledge on a given practice might reduce the chances of success of a physical activity-related PPP. The parts involved must ensure that professionals dealing with the participants are properly trained on the intervention. Lack of trust among personnel from different partners and power disputes are also reported.

Financial resources: The main challenges in this aspect deal with insecure funding, lack of long-term sustainability (which hampers the continuity of a project), and issues related to accountability (faulty reimbursement systems between partners and not including the PPP in the budgeting process). 
Pires et al.

Information and technology systems: Problems with documentation and information management (including lack of information and poorly stored records), unclear policies and regulations, and lack of standardization and monitoring are among the main challenges in this regard.

\section{CONCLUSIONS}

This article briefly discusses the usefulness and reliability of PPPs that make use of physical activity practices in the context of chronic disease prevention and public health promotion. The dynamics and procedures of these PPPs are somewhat similar to partnerships in other sectors, but some specificity regarding the employed procedures, long-term goals, and focus on the population should be acknowledged. As discussed, the establishment of such partnerships might be mutually advantageous, leading to benefits to both public and private entities, which would finally result in important benefits being offered to the population. Several factors indicate the need for such partnerships: the high morbidity and mortality of noncommunicable chronic diseases, the high costs associated with their treatment, the increasing trend of global prevalence of these diseases, the efficacy of physical activity on their prevention, limited resources for providing population-wide treatment, and successful reports of PPPs employing physical activity in health promotion. Based on these aspects, PPPs are valid and recommendable as an important part of public health policies and should be encouraged as a matter of reducing physical inactivity and preventing chronic noncommunicable diseases.

\section{Conflict of Interest}

This study has not been submitted elsewhere for publication, and all the listed authors have approved the enclosed manuscript. The authors have no conflicts of interest to declare.

\section{REFERENCES}

1. McRobbie MA, Kolbe LJ. The academy's pivotal role in supporting public-private partnerships to prevent chronic diseases. Prev Chronic Dis. 2009;6(2):A73

2. Easton A. Public-private partnerships and public health practice in the 21st century: looking back at the experience of the Steps Program. Prev Chronic Dis. 2009;6(2):A38.

3. Budreviciute A, Damiati S, Sabir DK, Onder K, Schuller-Goetzburg P, Plakys G, et al. Management and Prevention Strategies for Noncommunicable Diseases (NCDs) and Their Risk Factors. Front Public Health. 2020;8:574111.

4. Pate RR, Pratt M, Blair SN, Haskell WL, Macera CA, Bouchard C, et al. Physical activity and public health. A recommendation from the Centers for Disease Control and Prevention and the American College of Sports Medicine. JAMA. 1995;273(5):402-7.

5. Warburton DE, Nicol CW, Bredin SS. Health benefits of physical activity: the evidence. CMAJ. 2006;174(6):801-9.

6. Zhao M, Veeranki SP, Magnussen CG, Xi B. Recommended physical activity and all cause and cause specific mortality in US adults: prospective cohort study. BMJ. 2020;370:m2031.
7. Strain T, Brage S, Sharp SJ, Richards J, Tainio M, Ding D, et al. Use of the prevented fraction for the population to determine deaths averted by existing prevalence of physical activity: a descriptive study. Lancet Glob Health. 2020;8(7):e920-e30.

8. Hallal PC, Andersen LB, Bull FC, Guthold R, Haskell W, Ekelund $U$, et al. Global physical activity levels: surveillance progress, pitfalls, and prospects. Lancet. 2012;380(9838):247-57.

9. Forechi L, Mill JG, Griep RH, Santos I, Pitanga F, Molina MDCB. Adherence to physical activity in adults with chronic diseases: ELSA-Brasil. Rev Saude Publica. 2018;52:31.

10. Kohl HW, Craig CL, Lambert EV, Inoue S, Alkandari JR, Leetongin G, et al. The pandemic of physical inactivity: global action for public health. Lancet. 2012;380(9838):294-305.

11. World Health Organization. Global action plan on physical activity 2018-2030: more active people for a healthier world. Geneva; 2018.

12. McKinnon R. A case for public-private partnerships in health: lessons from an honest broker. Prev Chronic Dis. 2009;6(2):A72.
13. Putnam R. Bowling alone: the collapse and revival of American community. New York: Simon and Schuster; 2000.

14. Buse K, Walt G. Global public-private partnerships: Part II: What are the health issues for global governance? Bull World Health Organ. 2000;78(5):699-709.

15. Miller EK, Scofield JL. Slavic Village: incorporating active living into community development through partnerships. Am J Prev Med. 2009;37(6 Suppl 2):S377-85.

16. Estabrooks PA, Bradshaw $M$, Dzewaltowski DA, Smith-Ray RL. Determining the impact of Walk Kansas: applying a team-building approach to community physical activity promotion. Ann Behav Med. 2008;36(1):1-12.

17. Hamamoto MH, Derauf DD, Yoshimura SR. Building the base: two active living projects that inspired community participation. Am J Prev Med. 2009;37(6 Suppl 2):S345-51.

18. McCreedy M, Leslie JG. Get Active Orlando: changing the built environment to increase physical activity. Am J Prev Med. 2009;37(6 Suppl 2):S395-402. 
19. Lee $Y$, Yun L, Kim ML, Washington M. A Qualitative Systematic Review of Public-private Partnership in Promoting Physical Activity. Eval Health Prof. 2018:163278718796153.

20. Brasil. Lei $n^{\circ} 11.079$, de 30 de dezembro de 2004. Diário Oficial da União. 2004 Dez 31;1:6.

21. Australia. National Guidelines for Infrastructure Project Delivery [Internet]. Canberra: Department of Infrastructure, Transport, Regional Development and Communications; 2018 [cited 2021 Jun 14]. Available from: https://www.infrastructure.gov. au/infrastructure/ngpd/index.aspx

22. Canada. Guideline to Implementing Budget 2011 Direction on PublicPrivate Partnerships [Internet]. Ottawa: Treasury Board; 2012 [cited 2021 Jun 14]. Available from: https:// www.tbs-sct.gc.ca/pol/doc-eng. aspx?id=25576

23. Joudyian N, Doshmangir L, Mahdav M, Tabrizi JS, Gordeev VS. Publicprivate partnerships in primary health care: a scoping review. BMC Health Serv Res. 2021;21(1):4.

24. Bedi R. Public-private partnerships: an old solution to present challenges. J R Soc Promot Health. 2007;127(2):60.

25. Kraak VI, Story M. A public health perspective on healthy lifestyles and public-private partnerships for global childhood obesity prevention. J Am Diet Assoc. 2010;110(2):192-200.
26. Silversides A. Public-private partnerships, part 2: calculations of risk. CMAJ. 2008;179(10):991-4.

27. Tucker TJ, Makgoba MW. Public health. Public-private partnerships and scientific imperialism. Science. 2008;320(5879):1016-7.

28. Feyerherm L, Tibbits $M$, Wang $H$, Schram S, Balluff M. Partners for a Healthy City: Implementing Policies and Environmental Changes Within Organizations to Promote Health. Am J Public Health. 2014;104(7):1165-8.

29. Bornstein D, Pate R, Buchner D. Development of a National Physical Activity Plan for the United States. $J$ Phys Act Health. 2014;11(3):463-9.

30. Matsudo V, Matsudo S, Andrade D, Araujo T, Andrade E, de Oliveira L, et al. Promotion of physical activity in a developing country: The Agita Sao Paulo experience. Public Health Nutr. 2002;5(1A):253-61.

31. Matsudo $\mathrm{V}$. The role of partnerships in promoting physical activity: the experience of Agita Sao Paulo. Health Place. 2012;18(1):121-2.

32. Davis L, Loyo K, Glowka A, Schwertfeger R, Danielson L, Brea $C$, et al. A comprehensive worksite wellness program in Austin, Texas: partnership between Steps to a Healthier Austin and Capital Metropolitan Transportation Authority. Prev Chronic Dis. 2009;6(2):A60.
33. Hawkins C, O'Garro MA, Wimsett K. Engaging employers to develop healthy workplaces: the WorkWell initiative of Steps to a Healthier Washington in Thurston County. Prev Chronic Dis. 2009;6(2):A61.

34. Widdus R. Public-private partnerships for health: their main targets, their diversity, and their future directions. Bull World Health Organ. 2001;79(8):713-20.

35. McDonnell S, Bryant C, Harris J, Campbell MK, Lobb A, Hannon PA, et al. The private partners of public health: public-private alliances for public good. Prev Chronic Dis. 2009;6(2):A69.

36. Majestic E. Public health's inconvenient truth: the need to create partnerships with the business sector. Prev Chronic Dis. 2009;6(2):A39.

37. Jane B, Gibson K. Corporate sponsorship of physical activity promotion programmes: part of the solution or part of the problem? J Public Health (Oxf). 2018;40(2): 279-88.

38. Durant JT, Boivin TG, Pohl HR, Sinks TH. Public health assessment of dioxin-contaminated fish at former US airbase, Bien Hoa, Vietnam. Int J Environ Health Res. 2015;25(3):254-64. 